\title{
SMALL-SCALE BEST MANAGEMENT PRACTICES TO PROTECT LAKE WATER QUALITY
}

\author{
J. COBOURN \\ University of Nevada Cooperative Extension, Nevada, USA.
}

\begin{abstract}
Lake Tahoe, on the border of Nevada and California in the Sierra Nevada, is the world's 11th deepest lake and is one of the clearest high altitude lakes in the world. Since Secchi disk monitoring began in the late 1960s, average water transparency has decreased from over $30 \mathrm{~m}$ to about $20 \mathrm{~m}$. Efforts to reduce the decline in the water clarity of Lake Tahoe have been ongoing; since the early 1970s. One unique method to reduce nonpoint source pollution of the lake is the Best Management Practice (BMP) Retrofit program of the Tahoe Regional Planning Agency (TRPA). This bi-state agency requires all developed properties in the Lake Tahoe Basin to implement water quality BMPs. The TRPA has worked with local Conservation Districts, the USDA Natural Resources Conservation Service and University of Nevada Cooperative Extension to develop small-scale erosion control and runoff infiltration practices. Homeowners and small business owners can install these BMPs to reduce the amount of nutrient and fine sediment-bearing runoff flowing into street and highway storm drains from private properties. In turn, city and state road departments can design facilities sized only for the runoff from the public right-of-way. This saves city and state governments millions of dollars in infrastructure costs. Special techniques have been developed to capture runoff from rooftops and driveways, convey it to an infiltration system, and let it soak into the soil. Bare soil areas must be planted and/or covered with mulch to prevent erosion. Bare areas on slopes over 50\% must be treated with structures as well as vegetation. Building and landscape contractors are trained annually in proper BMP installation, and the textbook, How to Install Residential Scale Best Management Practices (BMPs) in the Lake Tahoe Basin, has been translated into Spanish. Lake monitoring since 2000 shows positive results.

Keywords: BMPs in Spanish, erosion control, infiltration system, Lake Tahoe, residential BMPs, small-scale best management practices, storm water, urban runoff, water quality, watershed management.
\end{abstract}

\section{INTRODUCTION}

Lake Tahoe, at an elevation of 6,225 feet in the Sierra Nevada in California and Nevada, is the 11th deepest lake in the world and is one of the clearest high altitude lakes in the world. It is a graben lake, formed after the block of crust beneath the lake's floor sank and the two adjacent blocks of the crust rose. The resultant trough was then dammed by volcanoes in the last 2 million years. Because the $800 \mathrm{~km}^{2}$ watershed is small relative to the $500 \mathrm{~km}^{2}$ surface area of the lake, the lake tends to be naturally oligotrophic, USFS [1].

When limnologist Dr. Charles Goldman of the University of California, Davis began monitoring water transparency with a Secchi disk in the late 1960s, the average water clarity was over $30 \mathrm{~m}$. By the end of the 20th century, the average clarity had steadily declined to an average of about $20 \mathrm{~m}$, Fig 1 .

\section{LOSS OF CLARITY RESULTS FROM URBANIZATION OF WATERSHED}

The Lake Tahoe watershed or basin is mostly forested, with rocky peaks rising 3000-4000 feet above the shoreline. Though its forests were logged during the Comstock mining boom of 1860 1900 , there was very little urban development until the 1950s, when towns and subdivisions began sprouting around the lakeshore. This urbanization accelerated after the 1960 Squaw Valley Winter Olympics and continued at a brisk pace till the early 1980s. Between 1960 and 1980, housing in the Tahoe Basin increased from 500 to 19,000 homes. By 1996, approximately $15 \%$ of the watershed 


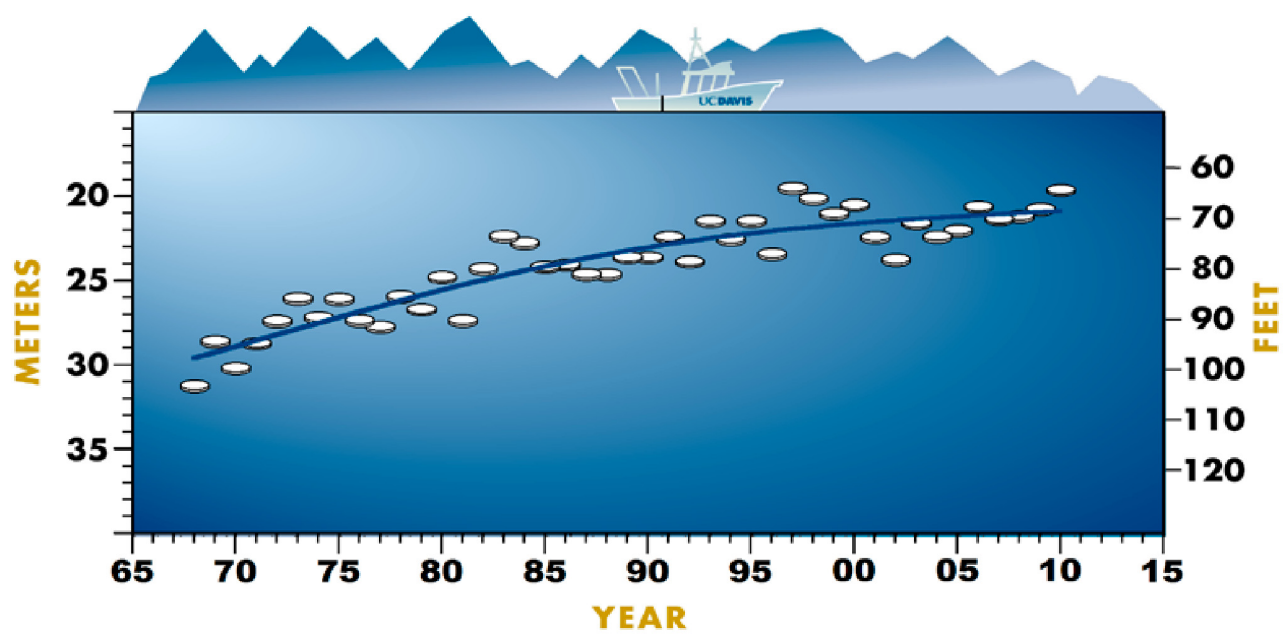

Figure 1: Decline of water clarity at Lake Tahoe, TERC [2].

\section{Before Development}

In a natural, undisturbed watershed, most rain and snowmelt are absorbed into the ground.

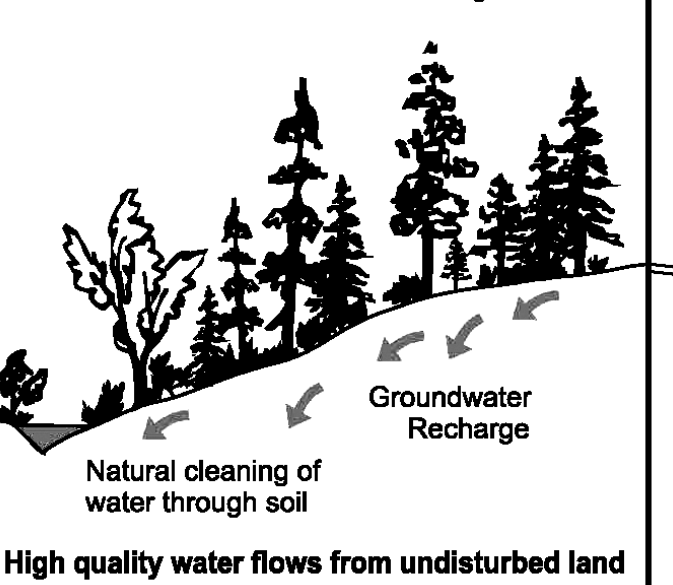

\section{After Development}

Rooftops and pavement cause most rain and snowmelt to run off the surface.

Figure 2: Storm water runoff from hard surfaces carries soil particles and other contaminants into nearby streams and eventually into the lake, Cobourn [3].

land area was developed for residential, commercial, recreational, and transportation uses, USFS [1]. In particular, the amount of impervious coverage of the ground by rooftops and pavement was enough to alter watershed processes. A significant portion of precipitation and snowmelt was converted to runoff rather than infiltrating into the soil. This runoff picked up soil particles from bare soil, roadside ditches, paved surfaces, and stream banks, and carried them into the lake in volumes not seen since the logging boom of the late 1800s, Fig. 2. 


\section{COMPREHENSIVE LAKE PROTECTION MEASURES OF THE LAST 40 YEARS} In 1969, the California and Nevada State Legislatures and the United States Congress formed the bi-state Tahoe Regional Planning Agency (TRPA) to enable planners and community leaders to cooperate on finding ways to prevent the cultural eutrophication of Lake Tahoe. At the urging of Dr. Charles Goldman, all properties using septic tank systems were required to hook up to municipal sanitary sewers, and wastewater treatment systems were upgraded to secondary processing. By 1975, almost all treated sewage effluent was exported from the Tahoe basin. These measures did a great deal to reduce nutrient pollution of the lake.

In the 1970s and 1980s, the Lake Tahoe Basin's largest landowner, the United States Forest Service (USFS), limited logging mainly to fuel wood and saw log sales. In the 1990s, the USFS conducted salvage sales after severe insect attacks, and then shifted primarily to fuel reduction and forest health management activities [1]. Throughout these decades, they upgraded the level of water quality best management practices (BMPs) being applied throughout the forest. The Forest Service received Federal funding starting in 1980 for an urban lot acquisition program which allowed government purchase of environmentally sensitive lots to prevent construction on steep or rocky sites, near streams or in wetlands.

In 1984, a Federal judge imposed a building moratorium for nearly 3 years, as the TRPA worked to build consensus among stakeholders to complete and adopt the Lake Tahoe Basin Regional Plan [4]. This Regional Plan established targets known as environmental thresholds. It would allow limited future development in the basin only to the degree that progress could be shown in attaining these thresholds. The Regional Plan included a Code of Ordinances [5] that limited environmental disturbance and imposed penalties for non-compliance. These regulatory powers have been controversial over the years, but public support for protecting the unique beauty of Lake Tahoe has always been relatively strong.

The four counties in the watershed, the City of South Lake Tahoe, and the Departments of Transportation of California and Nevada were also required to implement large-scale BMPs, especially in the public rights-of-way of streets and roads in the Tahoe Basin. Such BMPs included the stabilization of many cut and fill slopes along roads built across hillsides, the conversion of many miles of roadside ditches to lined storm drain systems, and the construction of numerous detention and sedimentation basins at the lower ends of these drainage systems.

\subsection{BMP retrofit required for all developed properties}

Chapter 25 of the TRPA Code of Ordinances [5] created the requirement that all properties, even those developed years or decades earlier, must be retrofitted with effective BMPs. This chapter sets high standards for the effectiveness of these practices. The BMPs have to be well designed and properly installed to mimic the natural processes of an undeveloped watershed. Chapter 25 requires that all the runoff produced by a $1 \mathrm{~h} / 20$ year 'design storm' (about 1 " of rain in $1 \mathrm{~h}$ ) must be infiltrated on the property, with none running down the driveway to reach municipal or county storm drain systems. All bare soil and slopes must be stabilized to prevent soil erosion and the delivery of sediment to public drainage systems. One obvious benefit of such BMPs is reduced infrastructure costs for public storm drain systems, which can be designed to carry just the runoff and sediment produced by public rights-of-way.

TRPA's BMP Retrofit Program was created primarily for residential properties and small commercial properties. (BMPs for large properties in urban centers and resort areas are governed and designed by a separate public process, which creates 'Community Plans'.) The relatively small size of most residences and small businesses, typically less than 1 acre, makes the BMP Retrofit Program 


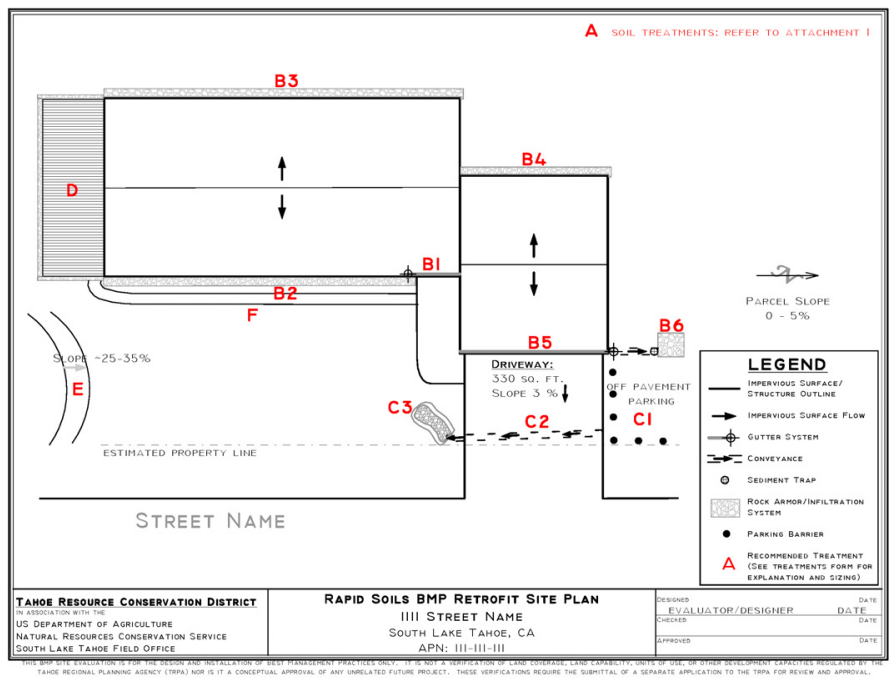

Figure 3: Site plan given to homeowner as part of a BMP Site Evaluation [3].

unique. The scope and scale of the BMPs is small by comparison with those used in large developments or jurisdictional projects governed by Community Plans. These small-scale BMPs are designed through analysis of the drainage patterns of each site, and they are usually installed by small crews or even by do-it-yourselfers. While post-construction BMPs are required in many other North American watersheds for new construction or remodels through the building permit process, the requirement for BMP Retrofit for all structures is extremely rare worldwide. (This author has not found one other instance of such a requirement for existing residences and small businesses.)

Nearly 30,000 single family residential homes were constructed in the Lake Tahoe Basin between 1950 and 2000. The owners of these properties can obtain a free BMP Site Evaluation by calling the TRPA or by calling the Tahoe Resource Conservation District (TRCD) for properties in California, or the Nevada Tahoe Conservation District (NTCD) for properties in Nevada. These agencies, along with the USDA Natural Resources Conservation Service (NRCS) and the University of Nevada Cooperative Extension, formed the 'BMP Retrofit Partners' in 2000 to assist property owners in implementing the required BMPs.

Property owners who request a BMP Site Evaluation are visited at their property by a staff member. This site evaluator makes a sketch of the property, noting the location of all impervious coverage (rooftops and pavement) and measuring the dimensions of these features. Using a constant head permeameter, the evaluator determines the permeability rate of the soil (slow or 'site constrained' $<1$ in $/ \mathrm{hr}$; moderately permeable $=1-13 \mathrm{in} / \mathrm{hr}$; and rapid permeability $>13 \mathrm{in} / \mathrm{hr}$ ). Other factors, such as slope, aspect, and proximity to a stream environment zone (SEZ) are also noted on the site evaluation form [3]. Within a month or so, the property owners receive a package of information, which includes a site plan for his or her property, Fig. 3, a list of recommended treatments, including the size and depth of any excavations, and a narrative description of the required practices.

Once a property owner receives the BMP Site Evaluation Report, he or she needs to install the practices or hire someone to do so. Along with the Site Evaluation Report, property owners receive a copy of the 150 page book, the Home Landscaping Guide for Lake Tahoe and Vicinity [6]. This publication gives homeowners information on the integration of BMPs with other landscape values, 
Table 1: Taxonomy of small-scale residential BMPs (as described in headings below).

(1) BMPs to capture and infiltrate runoff (see 4 below)

(a) Paving driveways and conveying runoff (see 4.1 below)

(i) Channel drains or trench drains (see 4.1 .1 below)

(ii) Driveway swales (see 4.1.2 below)

(b) Infiltration systems (see 4.2 below)

(i) Underground trenches and pits, including roof drip line infiltration trenches (see 4.2.1 below)

(ii) Above ground basins, swales, and natural infiltration (see 4.2 .2 below)

(2) Source control BMPs to reduce erosion (see 5 below)

(a) Gravel armor under decks and roof drip lines (see 5.1 below)

(b) Vegetating and mulching bare soil (see 5.2 below)

(c) Stabilizing steep slopes ( $>50 \%)$ with structures and vegetation (see 5.3 below)

such as fire defensible space, ease of maintenance, recommended native and adapted plants, wildlife habitat, and aesthetics.

In the year 2000, the University of Nevada Cooperative Extension took the lead in organizing the first Contractors BMP Workshop to educate contractors and landscape installers about how to install the recommended BMPs properly. These full day workshops have been repeated every year since, and hundreds of contractors have been trained in how to interpret a site evaluation and install BMPs on the ground. Participants receive a BMP manual, How to Install Residential Scale Best Management Practices (BMPs) in the Lake Tahoe Basin [3], which describes installation and maintenance procedures for the recommended small-scale BMPs. This manual has been translated into Spanish, and the author is available to offer these trainings to Spanish speaking audiences.

\subsection{What kinds of small-scale BMPs are required?}

BMP Retrofit applies to permanent, post-construction stabilization of each site. Construction site BMPs, also called Temporary BMPs, are required for all grading activities by city and county codes. These are not part of the BMP Retrofit Program. Also, building projects requiring a building permit are not a part of the BMP Retrofit Program. These 'new construction' projects will always need to implement post-construction BMPs. If these BMPs do not pass inspection, the property owner will not be able to recover a $\$ 2000$ construction bond posted to obtain the building permit.

Two general types of BMPs are required for BMP Retrofit. The first type includes all BMPs that 'Capture and infiltrate runoff' from impervious surfaces. The second general type is called 'Source control', and it consists of practices to control soil erosion from unvegetated areas and from slopes, Table 1.

\section{INFILTRATION BMPS KEEP RUNOFF FROM LEAVING THE PROPERTY}

BMPs to capture and infiltrate runoff can be subdivided into those for driveways (paving and creating conveyance of runoff) and those for underground or aboveground infiltration systems. In fact, these BMPs usually work in tandem, since any runoff on a driveway must be conveyed to an infiltration system so that it cannot flow off the property. 


\subsection{Paving driveways and conveying runoff}

All driveways are required to be paved, and they must be paved in such a way that runoff is captured and conveyed to an infiltration system on site. In the common instance when runoff might run down a driveway and into the street, a conveyance structure must be incorporated into the driveway to divert the flow to the side of the driveway, where a sediment trap and infiltration system must be constructed, Fig. 4. The use of permeable pavement is allowed for driveways, but TRPA requires a redundant infiltration system as well.

\subsubsection{Slotted drain conveyance (also called trench drain or channel drain)}

This BMP is a grated channel, installed slightly below the surface of the driveway, which transports runoff to an infiltration system, Fig. 5. This is the most effective method of conveyance for driveways,

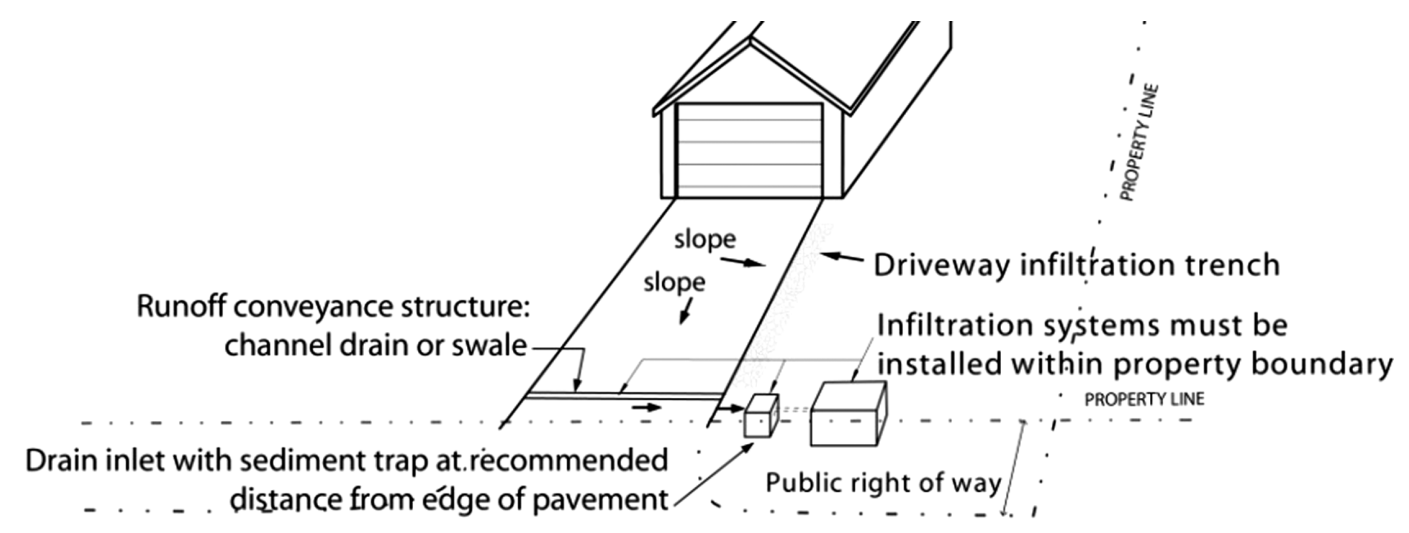

Figure 4: Driveway runoff can be conveyed by a drain or swale to an infiltration system [3].

\section{Driveway Runoff Conveyance System}

Slotted Channel Drain with Sediment Trap Next to Driveway

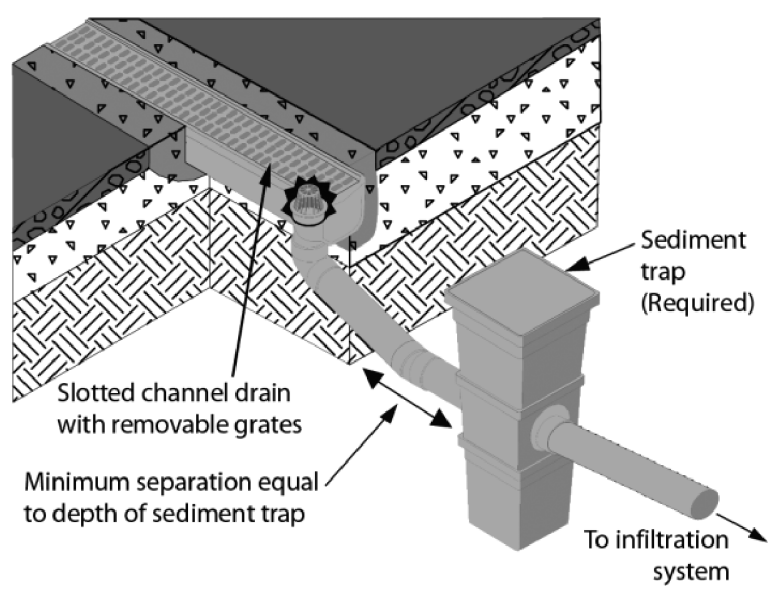

Figure 5: A channel drain or trench drain can keep runoff from reaching the street [3]. 
but it is often the most costly. Properly installed channel drains do not interfere with snow removal. There are several different types of slotted drains that can be installed. Be sure to choose one with removable grates that can be taken off to clean out accumulated debris as needed. Channel drains need a cleanable sediment trap to capture sediment before releasing storm water to the infiltration system [3].

\subsubsection{Driveway swale}

This structure is a wide and shallow linear depression in the pavement that transports water to an infiltration system or level, vegetated area. To install a swale (or channel drain) on a paved driveway, a portion of the pavement must be cut and removed. For a swale, the repaired pavement is shaped in a concave (V-shaped) form. On slopes greater than 5\%, swales may not be effective unless installed with a built-up section on the downhill side of the swale. (Removal of a larger section of pavement is required.) Swales angling down toward the infiltration system will divert and carry water more efficiently than swales installed perpendicular to the flow path. In cold climates, good swale design should consider the potential damage from snow plows. All changes in elevation need to be gradual. Cold patch berms constructed as swales on driveways will not last.

\subsection{Infiltration systems}

The infiltration of runoff from impervious surface takes several forms. These BMPs are designed to receive runoff directly from impervious surfaces or as concentrated flow from the outlet of a conveyance structure.

As noted, the Conservation Districts use the 20-year/1h 'design storm' when recommending treatments. Such a storm would deliver approximately $1^{\prime \prime}$ of rain in $1 \mathrm{~h}$. To design an infiltration system, the evaluator multiplies the square feet of pavement or roof area by the depth of the storm water $(1 "=$ $1 / 12$ foot) to derive the cubic feet of water that would need to be infiltrated near that surface. If the soil has a moderate infiltration/permeability rate, the runoff needs to be stored in a shallow basin or underground infiltration system that will allow all the water to infiltrate after the storm has ceased.

In 2000, infiltration trenches and other underground infiltration systems were usually excavated and then filled with 3/4" to $1 \frac{1 / 2}{\prime \prime}$ drain rock. By 2002, the BMP Retrofit Partners were recommending an alternative to gravel for the storage medium of infiltration systems. Prefabricated runoff storage units were being manufactured that could be placed inside an excavated infiltration trench, covered with filter fabric, and then covered with a plastic grid and 3" of gravel or sod, Fig. 6. These units are made of plastic. The main advantage to these units is that they have around $94 \%$ void space versus only about $40 \%$ void space for gravel. That means the amount of soil excavated is less than half as much as for the older gravel-filled systems. This, in turn, means that the property owner needs to incorporate and stabilize less than half as much excavated soil into other landscape features as with the larger rock-filled systems [3].

\subsubsection{Underground trenches and pits, including roof drip line infiltration trenches}

These infiltration systems are widely used on residential properties at Lake Tahoe. When storm water must be stored to allow time for its infiltration, most property owners excavate a pit or trench, fill it with a porous storage medium, and cover it up. These 'closed systems' are often recommended on-site evaluation forms, and the length, width, and depth of the system is calculated by the evaluator. The roof drip line infiltration trench is probably the most widely known representative of this category of BMPs, Fig. 7. Because excavated BMPs can fill with sediment during storms, ease of maintenance must be built into the design. At Lake Tahoe, property owners need to install a cleanable 


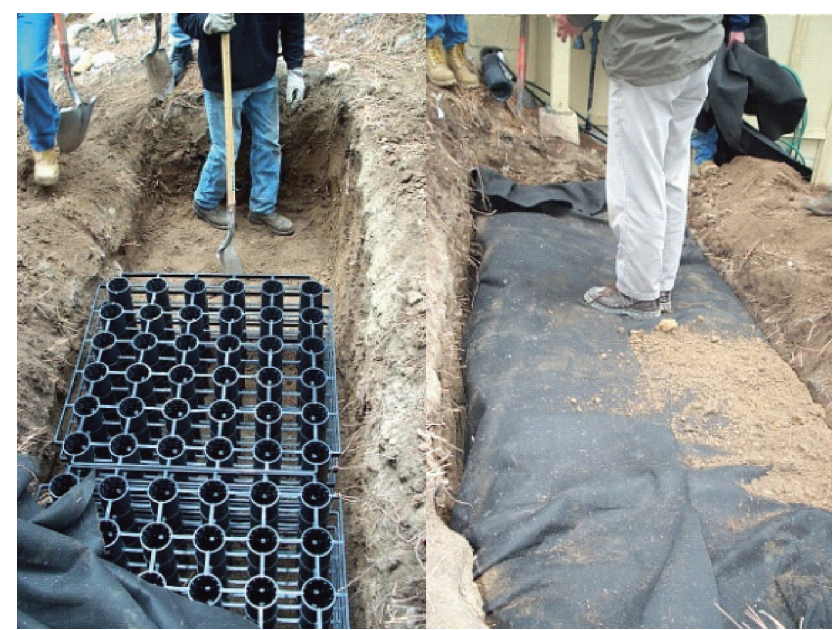

Figure 6: Infiltration systems filled with prefabricated storage units store more water than those filled with gravel. The tops and sides are wrapped with filter fabric and covered with gravel [6].

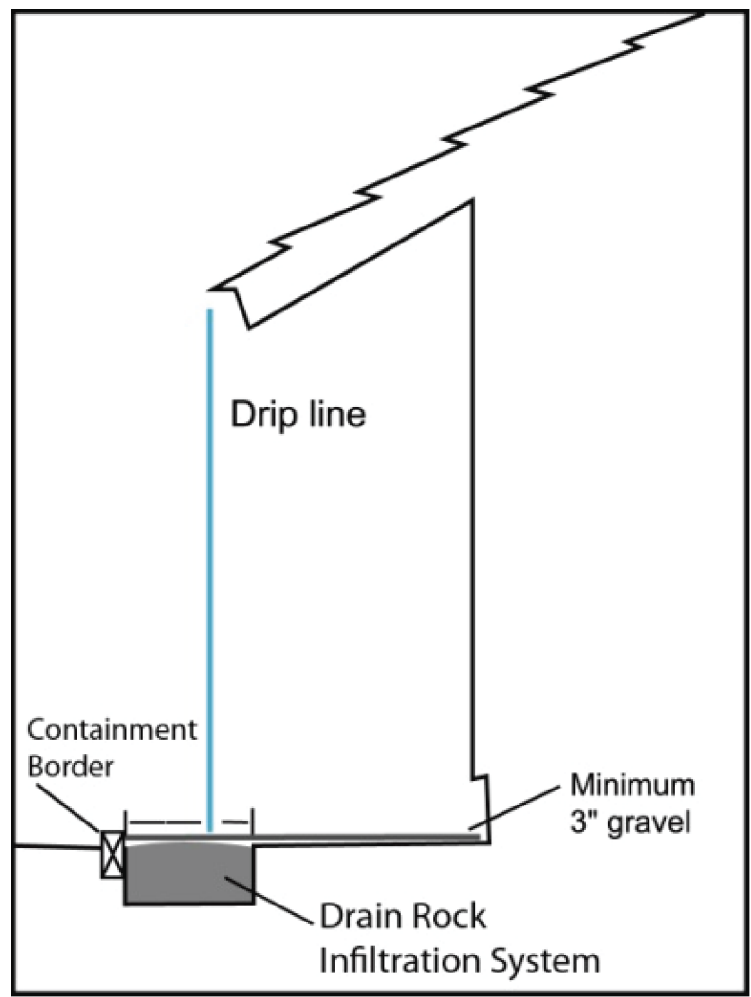

Figure 7: A roof drip line infiltration trench is inexpensive and effective. If the soil's permeability is rapid, a simple 3 " layer of gravel can armor the soil under the drip line and allow infiltration of roof runoff. Note containment border [6]. 
sediment trap between a driveway conveyance structure, such as a channel drain and an underground infiltration system.

Infiltration trenches are located adjacent to pavement and beneath roof eaves. Infiltration trenches are not appropriate on steep slopes, unless installed along the contour. When infiltration trenches run down a slope, they serve as conveyance structures, and their infiltration storage capacity is limited. Instead, use a drip line conveyance swale to deliver runoff to an infiltration system at the foot of the sloping drip line. In locations where runoff gathers upslope of a foundation, a subsurface drain should be placed under the drip line to convey the water to an infiltration system 10 feet away from the structure. Trenches filled with gravel should be bordered with larger rocks, bricks, concrete blocks, or treated lumber to keep it clean and in place. For fire defensible space, non-flammable borders must be used if they are within than 5 feet of a structure [3].

Infiltration systems are rectangular pits filled with drain rock or prefabricated storage units. These systems are used in locations requiring storage capacity for concentrated runoff, such as at the end of a conveyance structure from a driveway or at the foot of a drip line conveyance swale on a slope. Covered pits are also applicable at the foot of downspouts. If gravel is used to fill trenches, it should be $3 / 4^{\prime \prime}-1 \frac{1}{2}$ " in diameter and washed.

\subsubsection{Aboveground basins, swales, and natural infiltration}

As an alternative to underground or closed infiltration trenches, property owners can excavate infiltration basins or swales at the surface. In some cases, when the ground is flat, well vegetated, and has rapid permeability, runoff can simply be spread over the surface in a very simple BMP, called 'natural infiltration'.

Infiltration basins are shallow depressions in the ground or areas bordered by berms, which are designed to store and infiltrate runoff. The bottom of a basin can be covered by gravel, rocks, or dense vegetation, Fig. 8. A rock-armored spillway is incorporated to safely release overflow from basins in large rainstorms.

These aboveground systems, which store water till it can infiltrate, can be easier to maintain than underground systems. When the basin fills with sediment, the owner can easily see it and can remove and properly dispose of it, if the basin is designed with a gravel or turf bottom. In contrast, underground systems must be dug up and sometimes disassembled to remove sediment that prevents effective storage and infiltration.

Rain gardens are infiltration basins designed to make use of rain runoff as irrigation water. They work best on rapid permeability soil. The soil surface of rain gardens should be 6 " to 8 " lower than

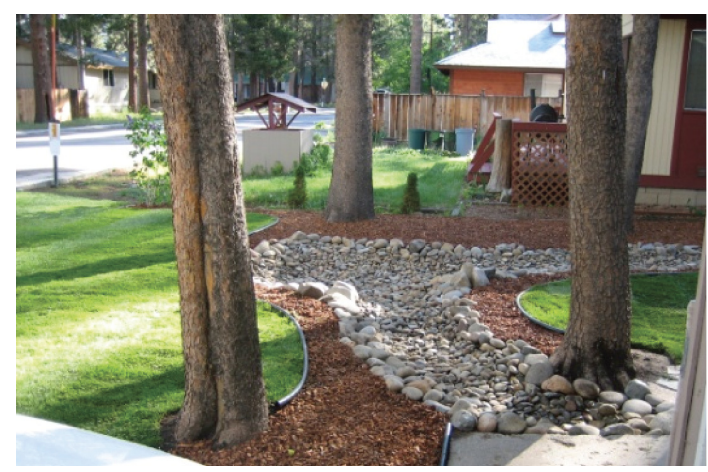

Figure 8: This infiltration basin will store roof runoff until it can percolate into the ground [3]. 
the surrounding soil. The rain garden must be designed to prevent standing water at the foundation. Vegetation in rain gardens should be dense and robust enough to stabilize soil by dissipating the energy from roof runoff. Drip or micro spray irrigation works well to establish and maintain attractive plants in areas of scarce rainfall [3].

An infiltration swale (grassed channel, dry creek bed) is a nearly level channel designed specifically to store and treat storm water runoff from nearby impervious surfaces, such as roads or driveways. As runoff flows into a channel, it is treated through filtering by the vegetation in the channel, filtering through a subsoil matrix, and infiltrating into the underlying soils. Ponds, basins, and swales can all be shaped to meet the aesthetic desires of the owners. A sediment trap or fore bay should pretreat sediment-laden runoff before entering swales or basins.

\section{SOURCE CONTROL BMPS ARE USED TO PREVENT SOIL EROSION}

Every site evaluation requires property owners to 'vegetate or mulch all bare soil areas'. When soil is compacted by foot or vehicle traffic, it can create runoff just as pavement does. Whatever its source, runoff erodes bare soil and carries it and attached nutrients through storm drains to streams and eventually to Lake Tahoe. Research indicates that the most cost effective way to protect Lake Tahoe is to keep soil in place on the landscape by protecting bare soil. On relatively flat terrain, vegetation and mulch can effectively stabilize soil and infiltrate runoff from developed areas, reducing erosion and effectively filtering sediment, Fig. 9.

\subsection{Gravel armor under decks and roof drip lines}

Gravel armor or mulch, also called inorganic mulch, can be used to armor soils which have rapid permeability. The gravel protects soil particles from the impact of the 'waterfall' of drops from the roof eave. On 'rapid soil', the minimum width of gravel armor placed 3" deep under drip lines without additional infiltration systems is $18^{\prime \prime}, 24^{\prime \prime}$, and $30^{\prime \prime}$ for 1-, 2- and 3-story roofs, respectively. Alternately, gravel mulch extending 5 feet out from the foundation meets fire defensible space

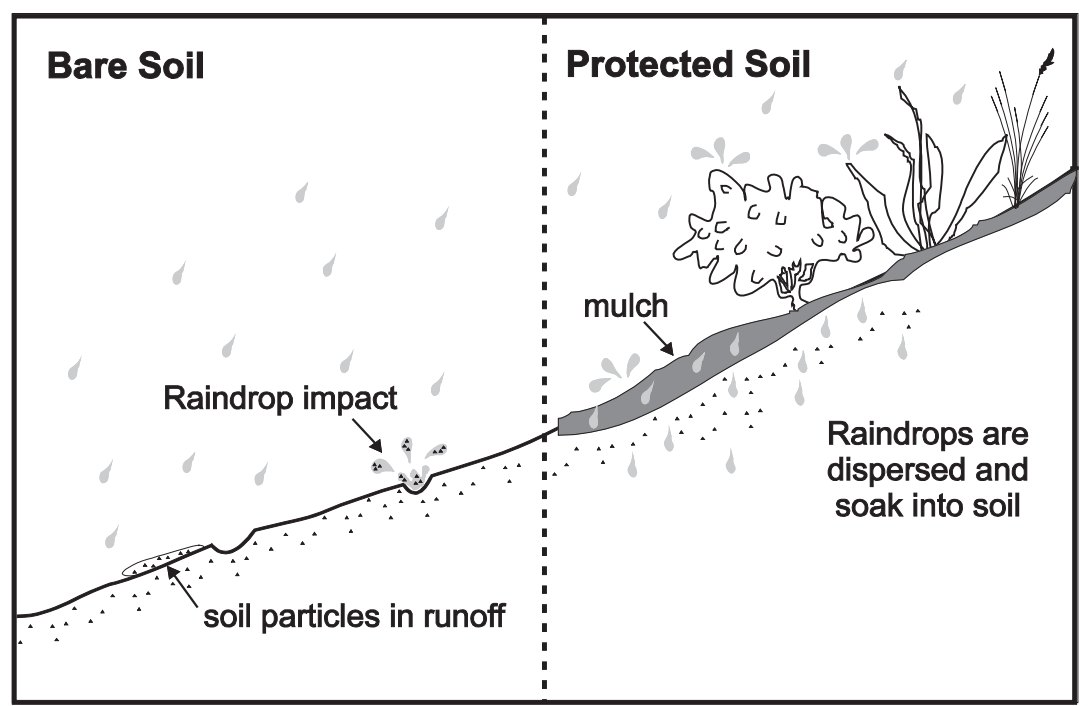

Figure 9: It is important to protect bare soil areas with vegetation and mulch [6]. 
criteria as well as soil protection standards. Gravel used to armor roof drip lines should be $3 / 4-1 \frac{1}{2}$ in diameter and washed. Three inches of gravel mulch is also used to prevent erosion caused by water falling through the cracks of elevated decks [3].

\subsection{Vegetating and mulching bare soil}

Because of the danger of wildfire in neighborhoods built adjacent to forests, the use of vegetation and mulch to cover and protect soil from erosion has been studied carefully in recent years. Within 5 feet of structures, property owners are encouraged to create a non-combustible area [7]. For this reason, many roof drip lines are covered with gravel or turf grass rather than woody shrubs.

In the area from 5 to 30 feet from structures, homeowners are encouraged to plant herbaceous (non-woody) plants, and to prevent the build-up of excess flammable materials or dense stands of shrubs or trees. Wood chips or other organic mulch can be used, but it should not create a continuous flammable surface that could carry a wildfire to the structure. The Home Landscaping Guide for Lake Tahoe and Vicinity [6] has a list of native and adapted plants that are recommended by TRPA for creating an attractive, weed-free landscape that is not prone to erosion.

\subsection{Stabilizing steep slopes ( $>50 \%)$ with structures and vegetation}

Bare soil is more vulnerable to erosion on slopes. Also, the steeper the slope, the more difficult it is to grow plants, Fig. 10. For this reason, the use of structural stabilization in combination with vegetation is the recommended BMP on slopes of more than $50 \%$. Site evaluators recommend use of low retaining walls and terracing to create flat or gently sloping planting surfaces for native and adapted plants. When rock slope protection or 'rip rap' is used on slopes, Fig. 11, property owners are encouraged to leave small planting holes every few feet along the rocky surface. In all cases on slopes of over 50\%, a combination of the structural stabilization with healthy vegetation provides the greatest control of soil erosion with the most aesthetically pleasing appearance, Fig. 12.

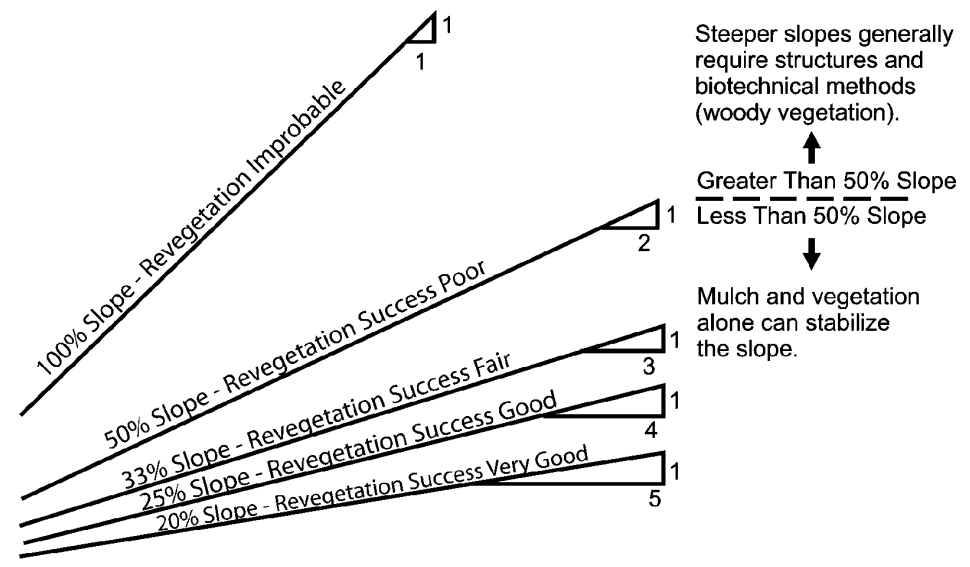

Figure 10: The steeper the slope, the more difficult it is to revegetate bare soil and stabilize the slope. A combination of structures and plants works best on slopes of 50\% and more [6]. 


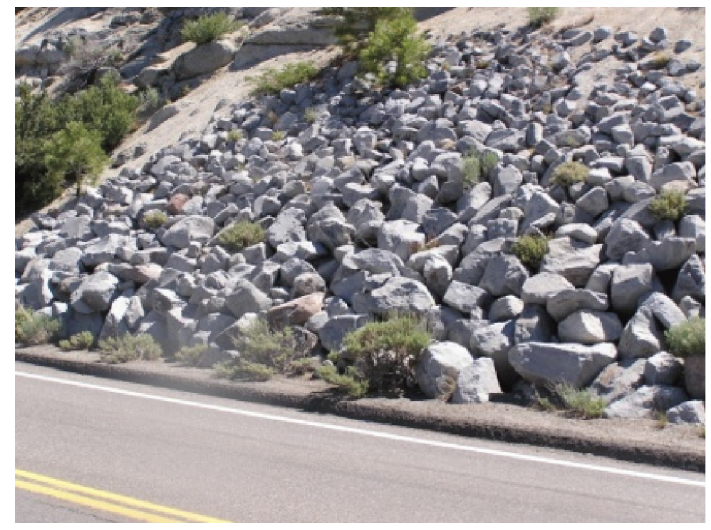

Figure 11: Rock slope protection or 'rip rap' can reduce erosion on bare slopes.

\section{RESULTS AND NEEDED RESEARCH}

The TRPA has relied mostly on public outreach education to encourage property owners to implement BMPs voluntarily. All property owners were supposed to implement the BMPs by 2008, but public response has not kept pace with the target of the ordinance. Less than half of the developed property owners in the Tahoe Basin have received a TRPA Certificate of BMP Completion. The most important reason given by survey respondents for their lack of compliance with the ordinance is the out-of-pocket cost of BMPS for the property owners, which can often be more than $\$ 5,000$. TRPA has begun to write enforcement letters to property owners. Commercial properties and multi-family residential properties were targeted first for enforcement, because they generally cause more runoff pollution than single family residences. Single family residences are now receiving enforcement letters. Once an owner has received an enforcement letter, he/she can still avoid a $\$ 4000$ fine as long as a BMP design is approved and steady progress is made to implement all recommendations.

While it is disappointing that some owners have failed to implement BMPs, there is good news too. Since the BMP Retrofit Program got rolling in 2000, over 13,000 property owners have implemented BMPs that meet TRPA requirements. While it may be coincidence, it is encouraging to note that in May 2008, scientists in charge of lake clarity monitoring at University of California, Davis, said that since 2001, the rate of clarity decline has slowed significantly, Fig. 1. From 1968 to 2000, there had been a near-continuous (straight line) decline in lake clarity [2].

There has been little research done on the effectiveness of the small-scale BMPs. A small number of case studies have been done, and the results have been interpreted primarily to point the direction for clarifying and improving installation procedures, in an intentional application of 'adaptive management'. Larger studies of the small-scale BMPs at Lake Tahoe could provide more information about what works best at the least cost to property owners.

\section{CONCLUSION - APPLICABILITY IN OTHER STATES AND COUNTRIES}

The work of the five BMP Retrofit Partner Agencies, the hundreds of contractors and the thousands of homeowners at implementing small-scale BMPs at Lake Tahoe has been groundbreaking. In combination with many other well-funded public programs aimed at mending the watershed disturbances caused by rapid urbanization, the contribution of private sector property owners has been significant. BMP Retrofit is the largest single project in the billion dollar Lake Tahoe Environmental Improvement 


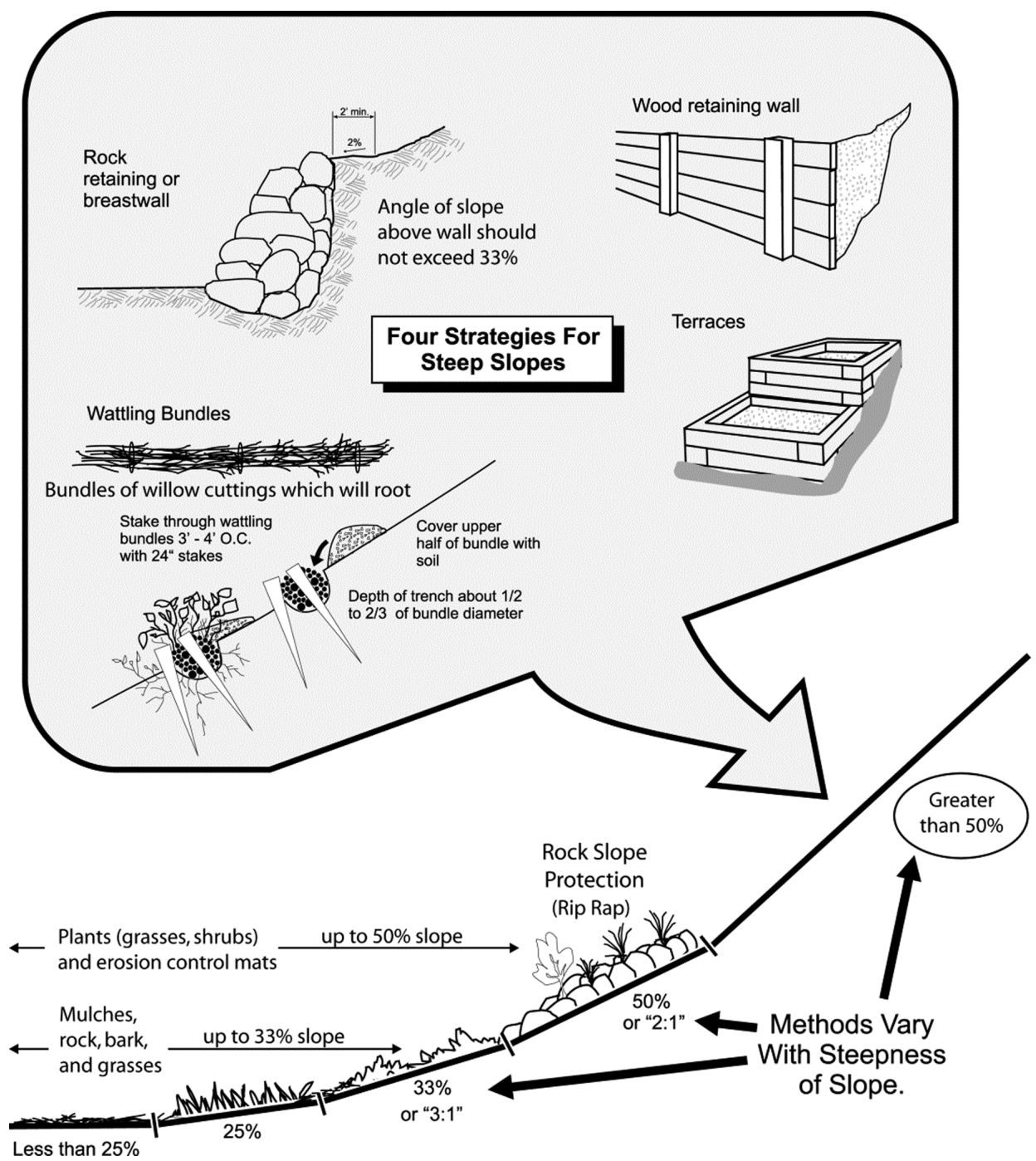

Figure 12: Methods used to control erosion vary with the steepness of slope, as shown by sloping lines at the bottom. For slopes over 50\%, structures hold the slope and create gradually sloping planting surfaces above [3].

Program [8], the comprehensive strategy of TRPA and other governmental agencies to halt the decline in Lake Tahoe's water quality. Scientists working on research for the Lake Tahoe Total Maximum Daily Load continue to regard the BMP Retrofit Program as an important component of the overall strategy to improve lake water quality, NDEP [9].

Watershed managers in other states and countries would do well to investigate the potential that smallscale BMPS may have for protecting water quality in their basins. The installation of these BMPS is a strategy that involves all landowners, intended at controlling nonpoint source pollution at its many small sources. It is relatively low tech and inexpensive compared to large engineered treatment systems. In 
areas where tourism and residential development are growing because of attractive rivers, lakes, or beaches, the lessons being learned in the Lake Tahoe Basin may be of great use. The BMP installation manual is also available in Spanish for international use [10].

\section{REFERENCES}

[1] USFS (USDA Forest Service), Lake Tahoe Watershed Assessment. Murphy, D. D. and Knopp, C.M, (Editors). Pacific Southwest Research Station, General Technical Report PSW-GTR-175. 2000. Online. http://www.fs.fed.us/psw/publications/documents/gtr-175/

[2] TERC (University of California Davis Tahoe Environmental Research Center), Tahoe: State of the lake report, 2011. Online. http://terc.ucdavis.edu/stateofthelake/StateOfTheLake2011.pdf

[3] Cobourn, J. How to install residential scale best management practices (BMPs) in the Lake Tahoe Basin, University of Nevada Cooperative Extension, 2011 CM-11-02, Online. http:// www.unce.unr.edu/publications/files/nr/2011/cm1102.pdf

[4] TRPA (Tahoe Regional Planning Agency), Regional Plan for the Lake Tahoe Basin. 1987. Online. http://www.trpa.org/default.aspx?tabindex $=4 \&$ tabid $=188$

[5] TRPA (Tahoe Regional Planning Agency), TRPA Code of Ordinances, 1989. Online. http:// www.trpa.org/default.aspx?tabindex $=2 \&$ tabid $=172$

[6] Cobourn, J., Carlos, W., Christopherson, J., Donaldson, S., Johnson, W., Post, R., Skelly, J. \& Smith, E. The Home Landscaping Guide for Lake Tahoe and Vicinity. University of Nevada Cooperative Extension, EB-06-01, 2006. Online. http://www.unce.unr.edu/publications/files/ nr/2006/eb0601.pdf

[7] Smith, E. Living with Fire: Lake Tahoe Basin, Second edition, University of Nevada Cooperative Extension, SP-06-11, 2008. Online. http://www.unce.unr.edu/publications/files/nr/2006/ sp0611.pdf

[8] TRPA (Tahoe Regional Planning Agency, Lake Tahoe Environmental Improvement Program (EIP), 1997. Online. http://trpa.org/default.aspx?tabid=227

[9] NDEP (Nevada Division of Environmental Protection), Final Lake Tahoe Total Maximum Daily Load Report, 2010. Online. http://www.ndep.nv.gov/bwqp/file/LTTMDL_Final_v20.pdf

[10] Cobourn, J. Como Instalar las Mejores Practicas de Manejo (BMP) a Escala Residencial en la Cuenca del Lago Tahoe, University of Nevada Cooperative Extension, CM-11-03, 2011. Online. http://www.unce.unr.edu/publications/files/s1/2011/cm1103.pdf 